\title{
Analysis of the relationship between the mutation site of the SLC39A4 gene and acrodermatitis enteropathica by reporting a rare Chinese twin: a case report and review of the literature
}

\author{
Wei Zhong ${ }^{1,2}$, Chao Yang ${ }^{3}$, Lei Zhu ${ }^{1,2}$, Yu-Qi Huang ${ }^{2}$ and Yong-Feng Chen ${ }^{3^{*}}$
}

\begin{abstract}
Background: Acrodermatitis enteropathica (AE) is a rare autosomal recessive hereditary skin disease caused by mutations in the SLC39A4 gene and is characterized by periorificial dermatitis, alopecia and diarrhoea due to insufficient zinc absorption. Only one of the three known sets of twins with AE has genetic information. This case reports the discovery of new mutation sites in rare twin patients and draws some interesting conclusions by analysing the relationship between genetic information and clinical manifestations.

Case presentation: Here, we report a pair of 16-month-old twin boys with AE exhibiting periorificial and acral erythema, scales and blisters, while subsequent laboratory examination showed normal plasma zinc and alkaline phosphatase levels. Further Sanger sequencing demonstrated that the patients were compound heterozygous for two unreported SLC39A4 mutations: a missense mutation in exon 5 (c.926G > T), which led to a substitution of the 309th amino acid residue cysteine with phenylalanine, a splice site mutation occurring in the consensus donor site of intron $5(c .976+2 \mathrm{~T}>\mathrm{A})$. A family study revealed that the boys' parents were heterozygous carriers of these two mutations.

Conclusion: We identified a new compound heterozygous mutation in Chinese twins with $A E$, which consisted of two previous unreported variants in exon 5 and intron 5 of SLC39A4. We propose an up-to-date review that different mutations in SLC39A4 may exhibit different AE manifestations. In conjunction with future research, our work may shed light on genotype-phenotype correlations in $\mathrm{AE}$ patients and provide knowledge for genetic counselling and treatment for $\mathrm{AE}$ patients.
\end{abstract}

Keywords: Acrodermatitis enteropathica, SLC39A4 gene, Mutation, Genotype-phenotype

\section{Background}

Acrodermatitis enteropathica (AE; OMIM 201100) is an autosomal recessive genetic disease that causes severe zinc deficiency and has an incidence rate of 1/500,000 [1]. The zinc deficiency is due to the SLC39A4 gene mutation, which limits the zinc absorption of the ZIP4 transporter in the small intestines, resulting in insufficient zinc absorption in the duodenum and jejunum [2]. Zinc is an

\footnotetext{
* Correspondence: gdcyf@163.com

${ }^{3}$ Dermatology Hospital of Southern Medical University, Guangzhou, China Full list of author information is available at the end of the article
}

essential coenzyme in metalloenzymes, including alkaline phosphatase; this enzyme regulates gene expression and is an important structural component of gene regulatory proteins, such as those required for intracellular binding of tyrosine kinases to $\mathrm{T}$ cell receptors [3]. Zinc can promote growth, sexual organ development and wound healing and has repairing effects on oral mucosa, hair, nails and other body parts [4]. Zinc deficiency can present in various clinical symptoms, such as growth retardation, decreased immune function and different skin or gastrointestinal injuries [5]. AE is classified as either hereditary

(c) The Author(s). 2020 Open Access This article is distributed under the terms of the Creative Commons Attribution 4.0 International License (http://creativecommons.org/licenses/by/4.0/), which permits unrestricted use, distribution, and reproduction in any medium, provided you give appropriate credit to the original author(s) and the source, provide a link to the Creative Commons license, and indicate if changes were made. The Creative Commons Public Domain Dedication waiver (http://creativecommons.org/publicdomain/zero/1.0/) applies to the data made available in this article, unless otherwise stated. 
or acquired and is characterized by periorificial dermatitis, alopecia and diarrhoea. These three symptoms simultaneously occur in only $20 \%$ of patients [6], usually during the weaning period of children, and they vary with age. Advanced AE symptoms may include neuropsychiatric disorders, hypogonadism, growth retardation and immune system dysfunction. Untreated patients with AE may eventually lead to multiple organ failure and death. Zinc deficiency accounts for $4 \%$ of morbidity and mortality in children aged from 6 months to 5 years worldwide [7]. Laboratory diagnosis requires the detection of zinc in serum, urine or hair, but the results are often unspecific and nonsensitive; thus, some patients with zinc levels can appear normal [2]. The zinc absorption test is cumbersome to use, and the SLC39A4 gene test can confirm the disease. Most clinicians rely on a zinc supplementation regimen $(1 \sim 5 \mathrm{mg} / \mathrm{kg})$ to predict clinical diagnosis with treatment outcomes [8]. The aforementioned regimen should be taken orally for a long time. If oral absorption is difficult, then it can be injected [6]. General treatment includes protein and vitamin supplementation and blood transfusion if necessary. Skin cleansing should be properly conducted to prevent infection.

\section{Case presentation}

We present the case of 16-month-old twin boys admitted to the hospital due to skin lesions that appeared 12 months after birth. The erythema of the oral region of the twins appeared one after the other, and a large area of erythema with a clear boundary and peeling was observed at the centre of the perianal portion. They came to our hospital due to ineffective treatment at the local hospital. The twins were born full term and breastfed for 7 months before weaning. In addition, the parents have a non-consanguineous marriage (Fig. 1).

The twins had normal physique, and no developmental delay was observed (older brother $9 \mathrm{~kg}, 78 \mathrm{~cm}$; younger brother $10 \mathrm{~kg}, 79 \mathrm{~cm}$ ). The skin was dry and dark, the mental state was poor, and the crying was weak.
Alopecia was not observed. The patients presented poor spirit and intermittent manic episodes. Symmetrical erythema appeared on the perioral region, hands, wrists, knees, feet and genital and perianal areas (Fig. 2). Complete blood cell count, liver and kidney function tests, serum zinc $(4.2 \mathrm{mg} / \mathrm{L}$; reference range $3.7-7.3 \mathrm{mg} /$ $\mathrm{L})$ and alkaline phosphatase levels (45 U/L, reference range 37-147 U/L) were within normal ranges. To confirm the diagnosis of $\mathrm{AE}$ for the two boys, direct sequencing analysis of SLC39A4 (ENST00000301305) was conducted on the family. The result showed that they were compound heterozygous for a novel missense mutation (c.926G $>\mathrm{T}$ ) in exon 5 and a novel splicing mutation in the donor site of intron $5(\mathrm{c} .976+2 \mathrm{~T}>\mathrm{A})$ in SLC39A4. Among the two mutations, c.926G $>$ T was originated from their mother, leading to a substitution of the 309th amino acid residue cysteine with phenylalanine (p.Cys309Phe), and c.976 + $2 \mathrm{~T}>\mathrm{A}$ was inherited from their father, suggesting that it would alter splicing of the mRNA of SLC39A4 (Table 1,Fig. 3). On these bases, the patients were diagnosed with $\mathrm{AE}$.

The twins were treated with approximately $1.4 \mathrm{mg} / \mathrm{kg}$ of zinc per day. Topical zinc oxide oil and paste were applied to the lesions and ulcers. Vitamin E cream was applied to the body to keep the skin moist. After 3 months of continuous medication, the lesions were completely resolved. After supplementing zinc for 1 year, the disease never relapsed (Fig. 4).

\section{Discussion and conclusions}

In the case, the boys had dermatitis at the ostium, accompanied by wrinkles, distal extremities and nail damage that appeared 5 months after weaning. And Sanger sequencing revealed that they were both compound heterozygous for c.926G > T and c. $976+2 \mathrm{~T}>\mathrm{A}$ in SLC39A4. And in silico analysis with the online software MutationTaster showed that both these two mutations were predicted to be disease causing. Then the final diagnosis of $\mathrm{AE}$ for the twins was made. After 2 weeks of zinc supplementation, the

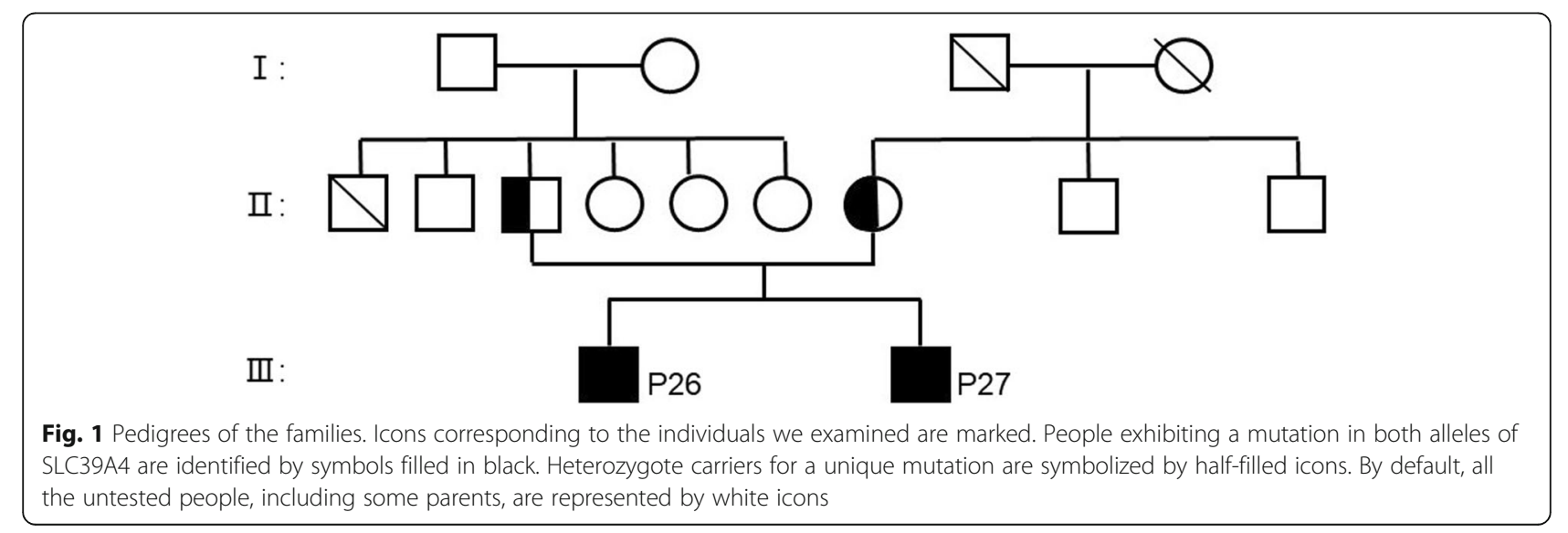



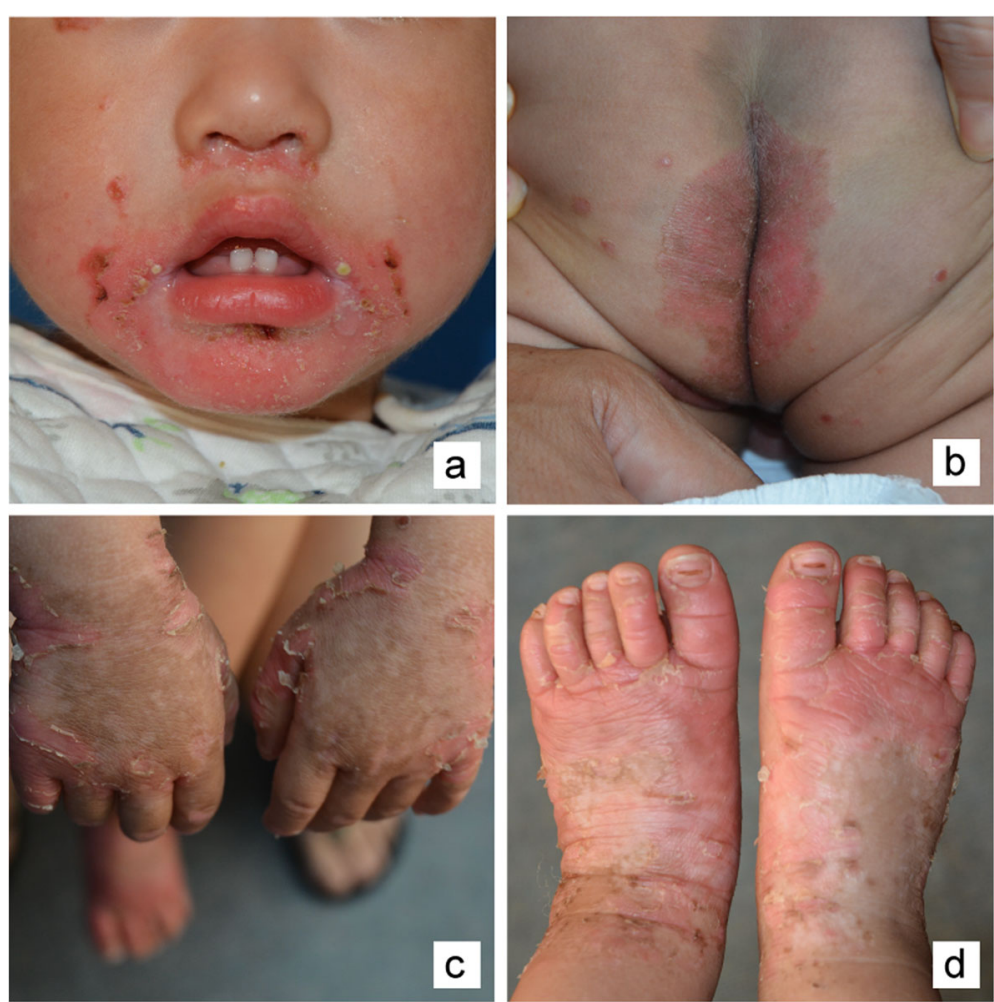

Fig. 2 Clinical photo of one of the twin patients: a Mouth-based face. $\mathbf{b}$ The perianal area has erythema with yellow-black sputum. c d The blisters are visible on both hands and feet

condition remarkably improved. On this basis, we diagnosed the twins with AE. Differential diagnoses to be considered were atopic dermatitis, Olmsted syndrome, congenital ichthyosis and biotinidase deficiency. After exclusion, the twins were orally supplemented with $1.4 \mathrm{mg} /$ $\mathrm{kg}$ zinc per day. No sign of recurrence was observed.

The human SLC39A4 gene covering approximately $4.5 \mathrm{~kb}$ of chromosomal region $8 \mathrm{q} 24.3$ consists of 12 exons and 11 introns [9]. According to the statistical results in Table 2 (refer to the Additional file 1: Table S1 for details), the average age of onset of $\mathrm{AE}$ was 9.81 months. Almost all patients had perioral skin or mucosal damage. Perineum partial dermatitis occurred in 92.59\% of patients, and two patients with exon 10 mutations were less prone to dermatitis in this area. Nail and other systemic impairments showed different clinical phenotypes due to variations in genetic mutation locations.
The proportions of dermatitis in the wrinkles of the trunk, extremities, nail damage, alopecia, diarrhoea, irritability and serum zinc levels were 71.43, 85.71, 42.86, $39.29,42.86,25$ and $67.86 \%$, respectively.

The four twins we currently know of are from Asian countries, including the twins we have described herein. These patients are identical twins, mainly with skin erythema blistering as the main manifestation, serological examination and lighter skin performance. Zinc supplementation was applied at $1-5 \mathrm{mg} / \mathrm{kg} . \mathrm{d}$, and the condition generally improved after approximately 2 weeks. Statistics have shown that the common high-frequency mutations of $\mathrm{AE}$ are in exons 9, 3 and 5 (Table 3). Missense mutations account for $71.43 \%$ of the gene phenotype. Exon 9 mutations can occur in men and women and have an average onset age of $15.86 \pm 9.21$ months. The clinical manifestations are mainly skin and mucosal damage. In addition to the common perioral and

Table 1 The details of the genetic variants found in this case

\begin{tabular}{|c|c|c|c|c|c|c|c|}
\hline Gene & $\begin{array}{l}\text { the chromosomal position } \\
\text { of the mutation }\end{array}$ & $\begin{array}{l}\text { the mRNA } \\
\text { accession }\end{array}$ & $\begin{array}{l}\text { nucleotide } \\
\text { changes }\end{array}$ & $\begin{array}{l}\text { protein changes in HUGO } \\
\text { gene nomenclature format }\end{array}$ & SIFT & PolyPhen & Mutation type \\
\hline SLC39A4 & $8 q 24.3$ exon 5 & $\begin{array}{l}\text { NM- } \\
130849\end{array}$ & c.926G > T & p.Cys309Phe (p.C309F) & 0.006 & $\begin{array}{l}\text { score:0.767; sensitivity: } 0.85 \\
\text { specificity: } 0.92\end{array}$ & missense \\
\hline SLC39A4 & $8 q 24.3$ intron 5 & $\begin{array}{l}\text { NM- } \\
130849\end{array}$ & c. $976+2 \mathrm{~T}>\mathrm{A}$ & - & - & - & $\begin{array}{l}\text { a splice site } \\
\text { mutation }\end{array}$ \\
\hline
\end{tabular}

"_" No information is displayed because the mutation site is located in the intron; SIFT: Score 0-0.05, predicted as damaging; PolyPhen: this mutation is predicted to be possibly damaging 


\section{Father}

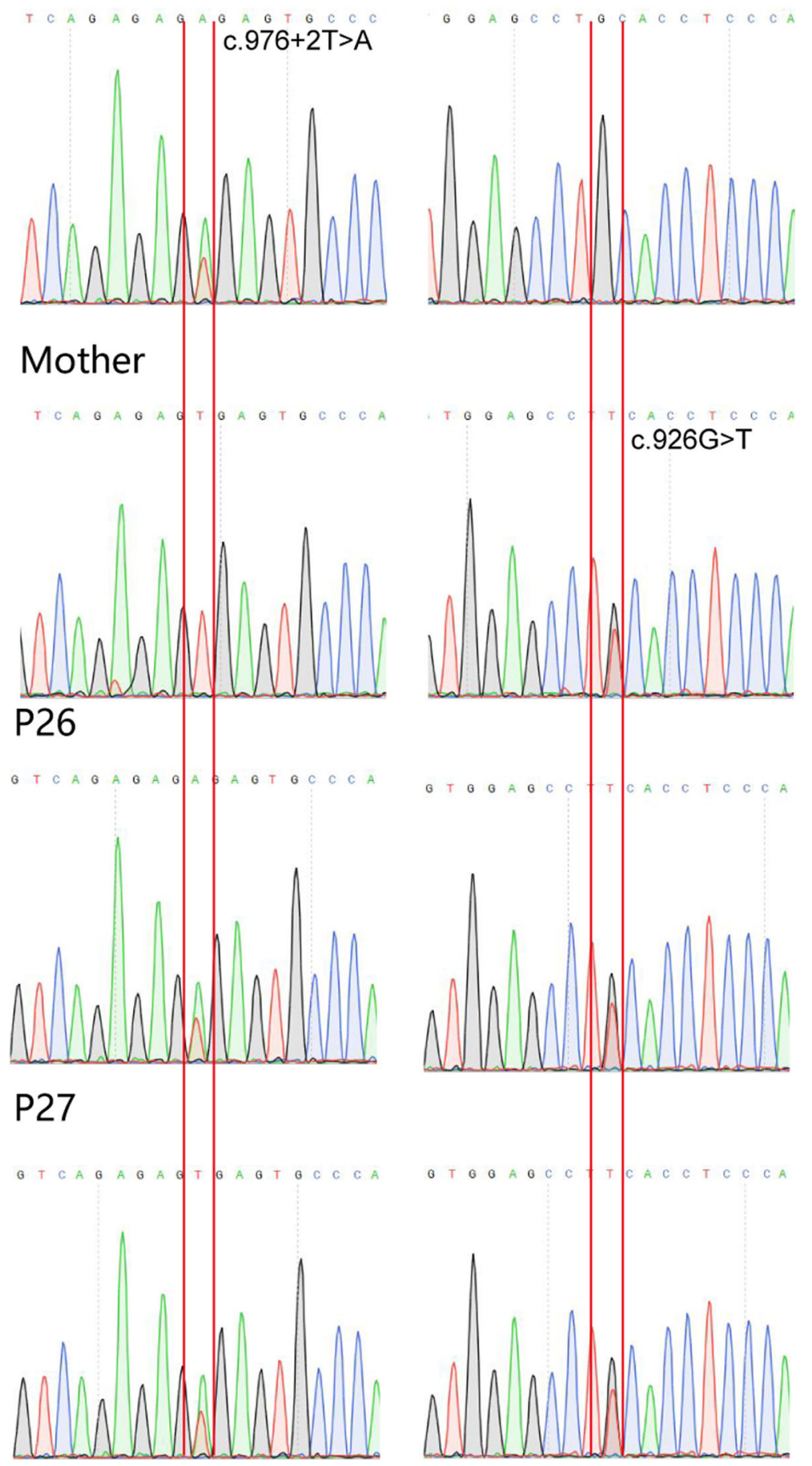

Fig. 3 Identification of heterozygous mutations in the SLC39A4 gene, one from the twins' father (c.976 + 2T > A) and the other from their mother (c.926G > T)

perineal lesions, the clinical phenotype of the exon 9 mutation has the following characteristics. The extremities and the folds of the trunk are often involved. Damage and growth retardation are rare. Symptoms, such as mental irritability, are almost non-existent.
Exon 3 mutations can occur in males and females with an average incidence of $6.25 \pm 1.71$ months. In addition to the classic three clinical manifestations of $\mathrm{AE}$, this type of mutation can have serious clinical symptoms, such as vertigo in the trunk folds and distal extremities. 

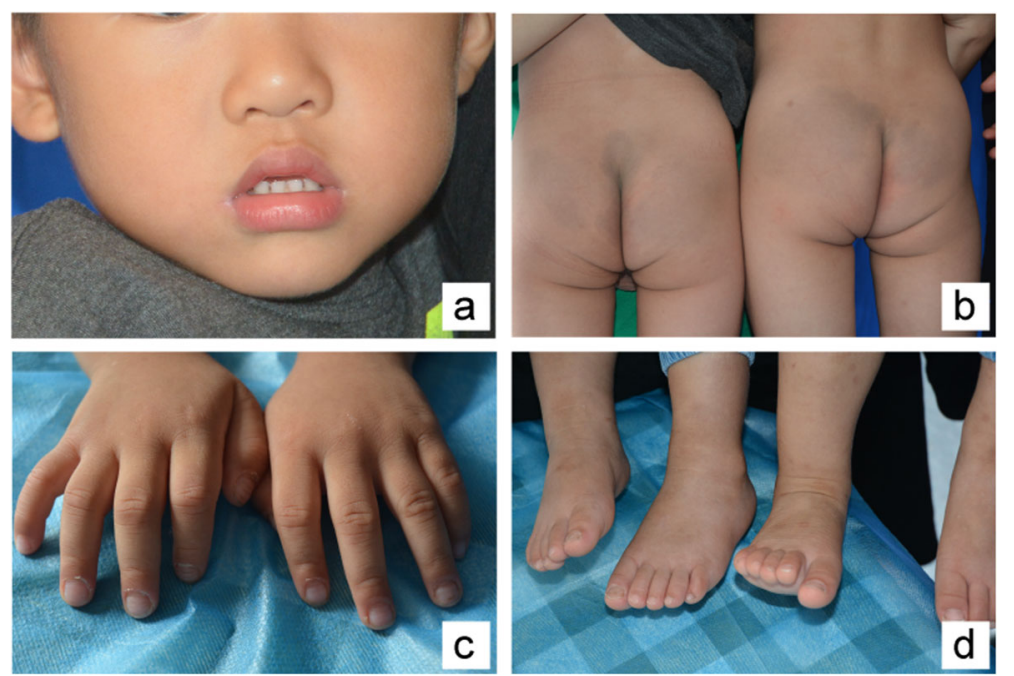

Fig. 4 Skin performance after 1 year of treatment with 16 months of twins: a Face. b Perineum. c Hands. d Feet

Table 2 Review the clinical features of AE patients in 27 cases

\begin{tabular}{|c|c|c|c|c|c|c|c|c|c|}
\hline patients & Age of onset (month) & Dermatitis site & Nail involvement & Alopecia & Diarrhea & Growth delay & Neuropsychiatric disorders & serum zinc levels & References \\
\hline$\overline{\mathrm{P} 1}$ & 7 & $1,2,3$ & 0 & 0 & 0 & 0 & 0 & 0 & [2] \\
\hline P2 & 10 & $1,2,3$ & 0 & 1 & 0 & 1 & 1 & 1 & [10] \\
\hline P3 & 6 & $1,2,3,4$ & 0 & 0 & 0 & 0 & 0 & 1 & [4] \\
\hline P4 & 60 & $1,2,3,4$ & 0 & 0 & 0 & 1 & 0 & 1 & [4] \\
\hline P5 & 2 & $1,2,3,4$ & 0 & 0 & 1 & 0 & 0 & 1 & [4] \\
\hline P6 & 10 & $1,3,4$ & 1 & 0 & 0 & 0 & 0 & 1 & [5] \\
\hline P7 & 10 & $1,3,4$ & 1 & 0 & 0 & 0 & 0 & 1 & [5] \\
\hline P8 & 7 & $1,3,4$ & 1 & 0 & 0 & 0 & 0 & 1 & [5] \\
\hline P9 & 12 & $1,2,3,4$ & 1 & 1 & 0 & 0 & 0 & 1 & [1] \\
\hline P10 & 8 & $1,3,4$ & 1 & 0 & 0 & 0 & 0 & 1 & [1] \\
\hline P11 & 5 & $1,2,3$ & 0 & 0 & 0 & 0 & 0 & 1 & [10] \\
\hline P12 & 5 & $1,2,3$ & 0 & 0 & 0 & 0 & 0 & - & [10] \\
\hline P13 & 8 & 1,4 & 1 & 0 & 1 & 0 & 0 & 0 & [11] \\
\hline P14 & 3 & $1,2,3,4$ & 1 & 1 & 1 & 1 & 1 & 1 & [12] \\
\hline P15 & 12 & $1,2,4$ & 0 & 1 & 1 & 0 & 0 & 1 & [13] \\
\hline P16 & 12 & 1,4 & 0 & 1 & 0 & 0 & 1 & - & [14] \\
\hline P17 & 12 & $1,2,3,4$ & 1 & 1 & 1 & 1 & 1 & - & [15] \\
\hline P18 & 12 & $1,3,4$ & 0 & 1 & 1 & 0 & 0 & 1 & [16] \\
\hline P19 & 5 & $1,2,3,4$ & 0 & 0 & 1 & 1 & 0 & 1 & [17] \\
\hline P20 & 2 & $1,2,3,4$ & 0 & 1 & 0 & 0 & 0 & 0 & [2] \\
\hline P21 & 15 & $1,2,3,4$ & 0 & 0 & 1 & 1 & 1 & 1 & [18] \\
\hline P22 & 7 & $1,2,3,4$ & 0 & 1 & 1 & 0 & 0 & 1 & [19] \\
\hline P23 & 1 & $1,2,3,4$ & 0 & 0 & 1 & 0 & 0 & 1 & [20] \\
\hline P24 & 5 & $1,2,3,4$ & 1 & 1 & 1 & 1 & 1 & 1 & [8] \\
\hline P25 & 5 & $1,2,3,4$ & 1 & 1 & 1 & 1 & 1 & 1 & [8] \\
\hline P26 & 12 & $1,2,3,4$ & 1 & 0 & 0 & 0 & 0 & 0 & this report \\
\hline P27 & 12 & $1,2,3,4$ & 1 & 0 & 0 & 0 & 0 & 0 & this report \\
\hline
\end{tabular}

Dermatitis site: Perioral $=1$,Torso fold $=2$, Limb end $=3$,Perineum $=4$; Other clinical manifestations: yes $=1$; no $=0$. Serum zinc levels: low $=1$, normal $=0$; " not available 
Table 3 Panel of SLC39A4 deleterious mutations noted in AE patients

\begin{tabular}{llll}
\hline & Exon 9 & Exon 3 & Exon 5 \\
\hline Number of patients & 7 & 4 & 3 \\
The gender ratio & $17.15 \%$ & $25.00 \%$ & 1 \\
gene mutation(Main) & missense & missense & missense \\
Age of onset (month) & $15.86 \pm 9.21$ & $6.25 \pm 1.71$ & $10.33 \pm 1.18$ \\
Perioral(N) & 1 & 1 & 1 \\
Torso fold(N) & 5 & 3 & 2 \\
Limb end(N) & 6 & 3 & 1 \\
Perineum(N) & 1 & 1 & 1 \\
Nail involvement(N) & 2 & 3 & 1 \\
Alopecia(N) & 3 & 1 & 0 \\
Diarrhea(N) & 3 & 3 & 0 \\
Growth delay(N) & 1 & 3 & 0 \\
Neuropsychiatric disorder(N) & 0 & 1 & 0 \\
low serum zinc levels(N) & 1 & 1 & 1 \\
therapeutic dose(mg/kg.d) & $2.64 \pm 1.03$ & $4.25 \pm 1.71$ & $1 \pm 0$ \\
course of treatment(day) & $14.86 \pm 2.06$ & $12.5 \pm 2.95$ & $14 \pm 0$ \\
\hline
\end{tabular}

The gender ratio: the ratio of men to the total number of people; the ratio of the number of patients with positive clinical manifestations to the total number of patients with the same type of gene mutation; $\mathrm{N}$ : number of patients with this symptom

Mutations include pustules and clam shells, severe nail depression, hair loss, diarrhoea growth retardation and intermittent mental irritability. Almost all patients with this type of mutation have decreased plasma zinc levels. The age of onset of the exon 3 mutation is lower than the average, and the clinical symptoms are heavy at onset stage. Multiple systemic damages may occur, thus requiring the clinician to give a large zinc supplementation dose. Similar to an early treatment, the prognosis is enhanced.

The exon 5 mutation in this article presents generally mild clinical manifestations. The patients were all male, and the average age of onset was $10.33 \pm 1.18$ months. Only vaginal dermatitis, nail apex irregularities, alopecia, diarrhoea and delayed growth were observed, and no mental symptoms appeared. Plasma zinc and alkaline phosphatase levels were unspecific, and oral zinc supplementation has improved rapidly, and long-term maintenance of low-dose zinc supplementation has achieved satisfactory results. This vitamin allows the body to slowly supplement zinc for a long time, is conducive to stimulating the absorption and metabolism of zinc in children, and substantially improves the disease and permits clinical treatment without the fear of long-term side effects.

In conclusion, we identified an unreported compound heterozygous mutation in SLC39A4 was discovered in Chinese twins with AE. Summary analysis revealed variations in the phenotypes caused by distinct exon mutations in this gene and in the severity and prognosis of the disease. This work provides several suggestions for clinical diagnosis and genetic counseling of $\mathrm{AE}$.

\section{Supplementary information}

Supplementary information accompanies this paper at https://doi.org/10. 1186/s12887-020-1942-4

Additional file 1: Table S1. Details of clinical features of AE patients in 27 cases.

Abbreviation

AE; OMIM 201100: Acrodermatitis enteropathica

Acknowledgements

Not applicable.

Authors' contributions

Analyzed and interpreted the data: ZW, YC, ZL, HYQ, CYF. Wrote the paper: $Z W$. All authors read and approved the final manuscript.

Funding

Not applicable.

\section{Availability of data and materials}

All data generated or analysed during this study are included in this published article.

\section{Ethics approval and consent to participate}

The family of the patients (Father and Mother) agreed that all family members participate in the genetic analysis portion of the study and signed informed consent, which has been explicitly approved by the ethics committee.

\section{Consent for publication}

The portrayal of clinical data and images in this study were signed with informed consent, which was obtained on behalf of the patient from the legal guardian.

\section{Competing interests}

The authors declare that they have no competing interests.

\section{Author details}

${ }^{1}$ Guangdong Medical College, College of Dermatology, Anhui Medical University, Guangzhou, China. ${ }^{2}$ Guangdong Provincial Dermatology Hospital, Guangzhou, China. ${ }^{3}$ Dermatology Hospital of Southern Medical University, Guangzhou, China.

Received: 9 October 2019 Accepted: 22 January 2020

Published online: 27 January 2020

\section{References}

1. Nakano H, Nakamura Y, Kawamura T, Shibagaki N, Matsue H, Aizu T, Rokunohe D, Akasaka E, Kimura K, Nishizawa A, et al. Novel and recurrent nonsense mutation of the SLC39A4 gene in Japanese patients with acrodermatitis enteropathica. Br J Dermatol. 2009;161(1):184-6.

2. Kilic SS, Giraud M, Schmitt S, Bezieau S, Kury S. A novel mutation of the SLC39A4 gene causing acrodermatitis enteropathica. Br J Dermatol. 2007; 157(2):386-7.

3. Ogawa $Y$, Kinoshita M, Shimada S, et al. Zinc and Skin Disorders. Nutrients 2018;10(2):11.

4. Hammersen J, Has C, Galiano M, Lindner M, Rossi R, Kohlhase J, Schneider $H$. Sustained need for high-dose zinc supplementation in children with Acrodermatitis Enteropathica. Clin Pediatr (Phila). 2018;57(1):99-102.

5. Nakano A, Nakano H, Nomura K, Toyomaki Y, Hanada K. Novel SLC39A4 mutations in acrodermatitis enteropathica. J Invest Dermatol. 2003;120(6): 963-6. 
6. Garza-Rodriguez V, de la Fuente-Garcia A, Liy-Wong C, Kury S, Schmitt S, Jamall IS, Ocampo-Candiani J. Acrodermatitis Enteropathica: a novel SLC39A4 gene mutation in a patient with Normal zinc levels. Pediatr Dermatol. 2015;32(3):e124-5.

7. Kambe T, Fukue $K$, Ishida R, Miyazaki S. Overview of inherited zinc deficiency in infants and children. J Nutr Sci Vitaminol. 2015;61(Suppl):S44-6.

8. Meftah SP, Kuivaniemi H, Tromp G, Kerkeni A, Sfar MT, Ayadi A, Prasad AS. A new mutation in exon 3 of the SCL39A4 gene in a Tunisian family with severe acrodermatitis enteropathica. Nutrition. 2006;22(10):1067-70.

9. Schmitt S, Kury S, Giraud M, Dreno B, Kharfi M, Bezieau S. An update on mutations of the SLC39A4 gene in acrodermatitis enteropathica. Hum Mutat. 2009;30(6):926-33.

10. Abu-Duhier F, Lovewell T, McDonagh A, Messenger A, Ibrahimi A, TaziAhnini R. First report of SLC39A4 mutation in acrodermatitis enteropathica family from the Middle East. Int J Dermatol. 2017;56(5):e97-e100.

11. Panzer R, Kury S, Schmitt S, Folster-Holst R. Identification of a novel mutation in the SLC39A4 gene in a case of Acrodermatitis Enteropathica. Acta Derm Venereol. 2016;96(3):424-5.

12. Kilic M, Taskesen M, Coskun T, Gurakan F, Tokatli A, Sivri HS, Dursun A, Schmitt S, Kury S. A zinc Sulphate-resistant Acrodermatitis Enteropathica patient with a novel mutation in SLC39A4 Gene. JIMD Rep. 2012;2:25-8.

13. Wang S, Xue L, Guo ZP, Wang L, Yang Y. A novel SLC39A4 gene mutation in the family of an acrodermatitis enteropathica patient with an unusual presentation. Br J Dermatol. 2008;159(4):976-8.

14. Lehnert T, Kury S, Burk G, Hoepffner W, Schuster V. Acrodermatitis enteropathica (AE) is caused by mutations in the zinc transporter gene SLC39A4. Klin Padiatr. 2006;218(4):221-3.

15. Zhou XY, Chen XJ, Wang S, Xue J, Liu W, Wang Q, Chen MH, Duan XL. One recurrent homozygous mutation of SLC39A4 in a girl with acrodermatitis enteropathica from southwestern China. Int J Dermatol. 2016;55(2):223-5.

16. Li CR, Yan SM, Shen DB, Li Q, Shao JP, Xue CY, Cao YH. One novel homozygous mutation of SLC39A4 gene in a Chinese patient with acrodermatitis enteropathica. Arch Dermatol Res. 2010:302(4):315-7.

17. Wu F, Zhang Y, Shi X, et al. Novel nonsense mutation of the SLC39A4 gene in a family with atypical acrodermatitis enteropathica. Clin Exp Dermatol. 2019;44(8):933-6.

18. Kharfi M, El Fekih N, Aounallah-Skhiri H, Schmitt S, Fazaa B, Kury S, Kamoun MR. Acrodermatitis enteropathica: a review of 29 Tunisian cases. Int J Dermatol. 2010;49(9):1038-44.

19. Park CH, Lee MJ, Kim HJ, Lee G, Park JW, Cinn YW. Congenital zinc deficiency from mutations of the SLC39A4 gene as the genetic background of acrodermatitis enteropathica. J Korean Med Sci. 2010;25(12):1818-20.

20. Jung AG, Mathony UA, Behre B, Kury S, Schmitt S, Zouboulis CC, Lippert U. Acrodermatitis enteropathica: an uncommon differential diagnosis in childhood - first description of a new sequence variant. J Dtsch Dermatol Ges. 2011;9(12):999-1002.

\section{Publisher's Note}

Springer Nature remains neutral with regard to jurisdictional claims in published maps and institutional affiliations.

Ready to submit your research? Choose BMC and benefit from:

- fast, convenient online submission

- thorough peer review by experienced researchers in your field

- rapid publication on acceptance

- support for research data, including large and complex data types

- gold Open Access which fosters wider collaboration and increased citations

- maximum visibility for your research: over $100 \mathrm{M}$ website views per year

At $\mathrm{BMC}$, research is always in progress.

Learn more biomedcentral.com/submissions 